\title{
DISPOSABLE CONTACT LENS-BASED OCULAR DELIVERY OF MOXIFLOXACIN : A NOVEL APPROACH
}

\author{
UMESH KUMAR SHARMA* \\ Department of Pharmaceutics, Mar Dioscorus College of Pharmacy, Thiruvananthapuram, Kerala, India. \\ Email: umeshpanditjp@gmail.com
}

Received: 20 August 2021, Revised and Accepted: 05 October 2021

\section{ABSTRACT}

Objective: In the present research, the main objective was to investigate the possibility of designing, fabricating, and optimizing a disposable ocular film-based drug delivery system.

Methods: Moxifloxacin hydrochloride was loaded onto the prepared disposable ocular films by the soaking method.

Results: The drug loading conditions were studied, and it was found that the maximum drug loading was achieved in 3 hours at pH 6.5 of the drug solution. It was also observed that the drug loading efficacy and in vitro drug release profile can be monitored by varying the ocular film composition. The ocular films were then characterized for thickness uniformity, size uniformity, weight uniformity, swelling index, surface pH, breaking on elongation, folding endurance, bio-adhesive strength, transparency, drug loading efficiency, moisture content, morphological characteristics, and in vitro drug release profiles.

Conclusion: Based on the results, it was concluded that the developed disposable ocular films demonstrate a significant prolonged drug release within the therapeutic range of up to $12 \mathrm{~h}$, which is promising as a novel disposable contact lens-based ocular drug delivery system.

Keywords: Disposable, Ocular films, Contact lenses, Chitosan, Activated silk fibroin, Snakeskin, Moxifloxacin, Ocular delivery.

(C) 2021 The Authors. Published by Innovare Academic Sciences Pvt Ltd. This is an open access article under the CC BY license (http://creativecommons.org/ licenses/by/4.0/) DOI: http://dx.doi.org/10.22159/ajpcr.2021v14i11.43090. Journal homepage: https://innovareacademics.in/journals/index.php/ajpcr

\section{INTRODUCTION}

A common approach for treating ocular disorders is using topical eye drops in the form of solutions and suspensions because of their convenient and non-invasive application [1-3]. However, only $5 \%$ of the drug administered enters the intraocular tissues, and the remaining $95 \%$ of the administered drug is wasted due to rapid drug clearance induced by a blink action, which also leads to poor drug bioavailability [4-6]. Therefore, frequent administration of eye drops is needed to maintain sustained therapeutic drug levels, which results in reduced patient compliance, increased local and systemic side effects, and increased treatment cost [1,7-9].

Disposable ocular films could be an interesting alternative approach to overcome these limitations [10-14]. The disposable ocular films could increase the residence time of the dosage form in the ocular cavity, leading to improved drug bioavailability, and minimised drug side effects, in addition to reduced treatment cost. Therefore, the idea of disposable contact lenses for ocular drug delivery is considered to be a non-invasive application that could eliminate multiple dose administrations and enhance patient compliance [15-17].

The poly (2-hydroxyethyl methacrylate) based conventional hydrogel contact lenses were examined for ocular drug delivery by soaking them in drug solution before insertion into the ocular cavity [18-20]. Although, they were found to be more effective than eye drops, their low drug loading efficacy and fast release characteristics were the limiting factors.

Pneumonia, conjunctivitis, endocarditis, tuberculosis, and sinusitis are a few types of infections which can be treated by moxifloxacin hydrochloride. Moxifloxacin belongs to the fluoroquinolone class of antibiotics and is represented as $\mathrm{C}_{21} \mathrm{H}_{24} \mathrm{FN}_{3} \mathrm{O}_{4}$. Mostly administered by mouth, IV or as eye drops, it shows a bioavailability of $86 \%$, an elimination half-life of $12.1 \mathrm{~h}$, and most of the administered drug is excreted from the body through urine and faeces $[21,22]$

The objective of this research was to explore the possibility of developing a film as biomaterials for disposable ocular film based ophthalmic drug delivery of Moxifloxacin hydrochloride. The effects of various combinations of additives and drug solution $\mathrm{pH}$ and time on drug loading, and drug release were studied. Properties such as transparency, thickness uniformity, size uniformity, folding endurance, bio-adhesive strength, drug loading efficiency, moisture content, and morphological characteristics were also investigated.

\section{MATERIALS AND METHODS}

\section{Materials}

The chitosan shrimp was obtained from Aura Biotechnologies Pvt. Ltd., Chennai, India, as gift sample. Bombyx mori raw silk yarns were obtained from Ashish Trading Company, Punjab as gift sample. Snakeskin pleated dialysis tube was obtained from Cole-polymer India, Mumbai as gift sample and moxifloxacin hydrochloride was obtained from Chromo Laboratories India Pvt. Ltd., as gift sample. Polyethylene glycol 400 (PEG400) was purchased from Merck, Hyderabad. All of the other chemicals and solvents were of the highest quality.

\section{Preparation of activated silk fibroin}

The raw silk yarns of $B$. mori were boiled with a $0.5 \%(\mathrm{w} / \mathrm{v})$ sodium carbonate solution for $2 \mathrm{~h}$ to remove sericin, a gummy material that adheres to the silk fibre. Then, the degummed silk yarns were rinsed with warm RO water and dried at $40^{\circ} \mathrm{C}$ for $12 \mathrm{~h}$. A 30:45:20:5 solution of calcium chloride $\left(\mathrm{CaCl}_{2}\right)$, calcium nitrate $\left(\mathrm{Ca}\left(\mathrm{NO}_{3}\right)_{2}\right)$, ethanol $\left(\mathrm{C}_{2} \mathrm{H}_{5} \mathrm{OH}\right)$, and water $\left(\mathrm{H}_{2} \mathrm{O}\right)$ was prepared. The silk yarns were then heated in the prepared solution at $85-90^{\circ} \mathrm{C}$ until a gel-like solution formed. The resultant gel is dialyzed against RO water using a snakeskin pleated dialysis tube at room temperature for $72 \mathrm{~h}$ to eradicate salt residual, 
and centrifuged at 15,000 rpm for 45 min to separate aggregates. The prepared activated silk fibroin solution was lyophilized and stored in self-sealing plastic pouches at $20^{\circ} \mathrm{C}$ for further use [23].

\section{Fabrication of ocular films}

The ocular films were prepared by the casting method. The $2 \%(\mathrm{w} / \mathrm{v})$ solution of chitosan shrimp in acetic acid, the $2 \%(\mathrm{w} / \mathrm{v})$ solution of activated silk fibroin gel in deionized water, and $25 \%(\mathrm{w} / \mathrm{w})$ of PEG 400 in the polymer matrix were mixed at $200 \mathrm{rpm}$ for 30 min using a magnetic stirrer. The ocular films were prepared using different ratios of chitosan and activated silk fibroin solution (Table 1). The mixtures were then poured onto the glass molds and dried in a hotair oven at $60^{\circ} \mathrm{C}$. The dried films were cut into $15 \mathrm{~mm}$ round shapes using a stainless steel cutting mold and dipped in $1 \mathrm{M}$ sodium hydroxide solution for $20 \mathrm{~min}$, and the $\mathrm{pH}$ was neutralized by repeatedly rinsing with deionized water. The prepared ocular films were then immersed in $0.01 \mathrm{M}$ phosphate buffer saline solution, $\mathrm{pH} 7.4$ for $36 \mathrm{~h}$ and sterilized at $121^{\circ} \mathrm{C}$ and $15 \mathrm{psi}$ for $20 \mathrm{~min}$ in autoclave $[24,25]$. The sterilized ocular films were stored for further use.

\section{Estimation of therapeutic dose}

The estimated therapeutic dose of moxifloxacin was calculated. The moxifloxacin eye drop solution $(0.5 \% \mathrm{w} / \mathrm{v})$ is commonly prescribed at 1 drop 4 times a day. Assuming 1 drop is equal to $50 \mu$, the daily moxifloxacin eye drop dose is $200 \mu \mathrm{l}$, equivalent to $1000 \mu \mathrm{g}$ of Moxifloxacin [26,19]. However, the ocular bioavailability of moxifloxacin through eye drop therapy is only $1 \%$, which indicates that the therapeutic requirement of moxifloxacin is $10 \mu \mathrm{g} /$ day $[27,28]$. However, several studies have proved that the bioavailability of drugs to target tissue is more than $50 \%$ through ocular drug delivery. Moxifloxacin ocular films have a therapeutic requirement of $20 \mu \mathrm{g} /$ day, assuming $50 \%$ bioavailability [29-31].

\section{Drug loading to ocular films}

A $0.5 \%$ solution of moxifloxacin hydrochloride (Fig. 1) in $0.01 \mathrm{M}$ phosphate buffer solution was prepared, and the solution was sterilized by the filtration method using a $0.22 \mathrm{~m}$ pore size membrane filter. Then, the prepared and autoclaved ocular films were soaked in $2 \mathrm{ml}$ of $0.5 \%$ Moxifloxacin solution for $1-24 \mathrm{~h}$. The $\mathrm{pH}$ of the drug solution was varied from 6.5 to 8.0 at room temperature in a laminar flow hood [32-34]. The fabricated drug-loaded ocular films were preserved for further use (Tables 2 and 3).
Physical evaluation of ocular films

The fabricated drug-loaded ocular films were evaluated for their physical and drug release properties. The key evaluation parameters are as follows:

\section{Size uniformity}

The uniformity of size is an important parameter, which determines the drug content of the fabricated ocular films. The size of the films was measured using a vernier caliper. The average size of the optimized batch was reported in Table 4.

\section{Thickness uniformity}

The uniformity of drug content in the lens and also its aesthetic value, to an extent, are determined by thickness uniformity. The thickness can be measured using a digital screw gauge (Mitutoyo MMO-25DS) at the center and at four positions around the perimeter of the hydrated films, and then the average thickness was calculated [35] and reported in Table 4.

\section{Weight consistency}

The fabricated lenses were weighed using a digital balance and weight variation was determined to ensure content uniformity, since deviation in uniform weight is due to a difference in the amount of either drug or the ocular film contents in an individual film. The average weight of optimized fabricated films was reported in Table 4.

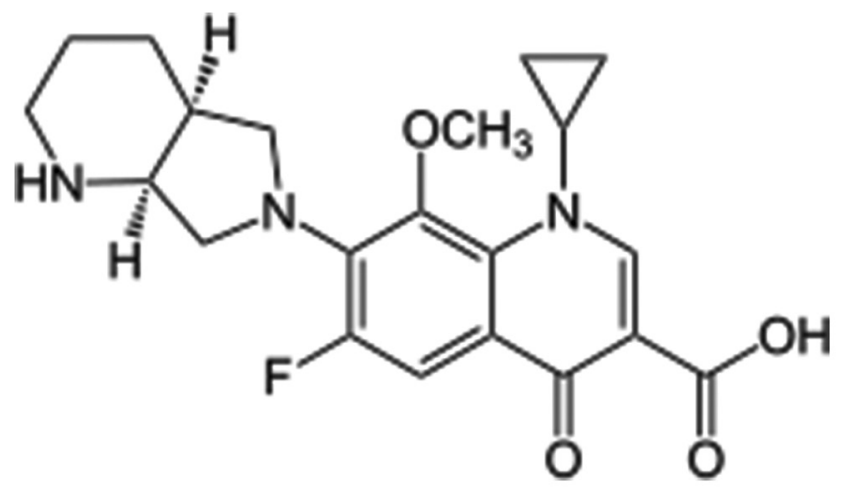

Fig. 1: Moxifloxacin hydrochloride

Table 1: Composition of fabricated ocular films

\begin{tabular}{|c|c|c|c|c|c|c|c|c|c|}
\hline \multirow[t]{2}{*}{ Ingredients } & \multicolumn{9}{|c|}{ Formulation No. } \\
\hline & OF-01 & OF-02 & OF-03 & OF-04 & OF-05 & OF-06 & OF-07 & OF-08 & OF-09 \\
\hline Chitosan shrimps solution (\%) & 90 & 80 & 70 & 60 & 50 & 40 & 30 & 20 & 10 \\
\hline Activated silk fibroin gel (\%) & 10 & 20 & 30 & 40 & 50 & 60 & 70 & 80 & 90 \\
\hline PEG $400(\% \mathrm{w} / \mathrm{w})$ & 25 & 25 & 25 & 25 & 25 & 25 & 25 & 25 & 25 \\
\hline
\end{tabular}

Table 2: Effect of time on drug loading capacity

\begin{tabular}{|c|c|c|c|c|c|c|c|c|}
\hline \multirow[t]{2}{*}{ Formulation } & \multicolumn{8}{|c|}{ Drug loading $(\mu \mathrm{g})$ of ocular film } \\
\hline & $1 \mathrm{~h}$ & $2 \mathrm{~h}$ & $3 \mathrm{~h}$ & $4 \mathrm{~h}$ & $5 \mathrm{~h}$ & $6 \mathrm{~h}$ & $12 \mathrm{~h}$ & $24 \mathrm{~h}$ \\
\hline OF - 01 & $05.32 \pm 0.56$ & $07.32 \pm 0.42$ & $09.75 \pm 0.32$ & $09.78 \pm 0.44$ & $09.78 \pm 0.35$ & $09.78 \pm 0.40$ & $09.76 \pm 0.21$ & $09.75 \pm 0.23$ \\
\hline OF - 02 & $06.84 \pm 0.52$ & $08.25 \pm 0.34$ & $10.38 \pm 0.26$ & $10.38 \pm 0.36$ & $10.39 \pm 0.54$ & $10.37 \pm 0.34$ & $10.37 \pm 0.36$ & $10.36 \pm 0.50$ \\
\hline OF - 03 & $07.58 \pm 0.63$ & $09.56 \pm 0.52$ & $12.86 \pm 0.52$ & $12.88 \pm 0.28$ & $12.89 \pm 0.36$ & $12.87 \pm 0.66$ & $12.87 \pm 0.40$ & $12.86 \pm 0.36$ \\
\hline OF -04 & $08.06 \pm 0.18$ & $13.67 \pm 0.42$ & $28.56 \pm 0.23$ & $28.72 \pm 0.32$ & $28.88 \pm 0.28$ & $28.92 \pm 0.24$ & $28.82 \pm 0.33$ & $28.44 \pm 0.28$ \\
\hline OF - 05 & $09.53 \pm 0.51$ & $12.23 \pm 0.51$ & $18.89 \pm 0.28$ & $24.62 \pm 0.25$ & $24.62 \pm 0.33$ & $24.61 \pm 0.48$ & $24.60 \pm 0.52$ & $24.59 \pm 0.52$ \\
\hline OF -06 & $10.84 \pm 0.32$ & $12.85 \pm 0.43$ & $17.32 \pm 0.22$ & $17.33 \pm 0.28$ & $17.32 \pm 0.36$ & $17.32 \pm 0.25$ & $17.31 \pm 0.18$ & $17.30 \pm 0.42$ \\
\hline OF - 07 & $11.56 \pm 0.51$ & $12.52 \pm 0.36$ & $18.56 \pm 0.18$ & $18.56 \pm 0.44$ & $18.56 \pm 0.38$ & $18.55 \pm 0.24$ & $18.54 \pm 0.32$ & $18.53 \pm 0.22$ \\
\hline OF - 08 & $12.32 \pm 0.43$ & $13.01 \pm 0.62$ & $18.92 \pm 0.23$ & $18.92 \pm 0.50$ & $18.92 \pm 0.33$ & $18.91 \pm 0.36$ & $18.91 \pm 0.25$ & $18.90 \pm 0.34$ \\
\hline OF - 09 & $12.89 \pm 0.71$ & $13.94 \pm 0.35$ & $19.23 \pm 0.44$ & $19.23 \pm 0.32$ & $19.22 \pm 0.26$ & $19.21 \pm 0.52$ & $19.20 \pm 0.55$ & $19.92 \pm 0.40$ \\
\hline $\mathrm{CCL}^{\#}$ & $01.31 \pm 0.38$ & $02.24 \pm 0.44$ & $03.86 \pm 0.61$ & $5.01 \pm 0.32$ & $07.32 \pm 0.21$ & $08.98 \pm 0.25$ & $14.82 \pm 0.23$ & $26.46 \pm 0.30$ \\
\hline
\end{tabular}

Condition: Moxifloxacin solution (0.5\%), pH 6.5; SD: Standard deviation; $\mathrm{n}=3$, \#Commercial contact lenses 


\section{Light transparency}

The light transparency of the fabricated ocular films was determined using a ultraviolet (UV)-visible spectrophotometer. The hydrated films were glued to the quartz cuvette's outer surface. The cuvette was placed in the spectrophotometer and the visible light transparency was measured at 381-780 $\mathrm{nm}$ [36] and reported in Table 4.

\section{Swelling index}

The swelling index is determined using stimulated tear fluid. Each fabricated ocular film was weighed and immersed in $5 \mathrm{~mL}$ of stimulated tear fluid. An increase in the weight of the film was determined at pre-set time intervals until a constant weight was seen. The degree of swelling was calculated using equation 1 and reported in Table 4.

Swelling index $=$ Weight after swelling-Initial weight/Initial weight

\section{Moisture content}

The moisture content of the fabricated ocular films may influence the mechanical strength and drug release behavior. Therefore, the moisture content of the film was estimated by keeping the film under vacuum desiccation until constant weight was obtained. The percentage moisture content was calculated [36] using equation 2 and was reported in Table 4.

\%Moisture content $=$ (Initial weight-Final weight $/$ Initial weight) $\times 100$

\section{Surface $\mathrm{P}^{\mathrm{H}}$}

To determine surface $\mathrm{pH}$ of ocular films, the fabricated films were left to swell for $1 \mathrm{~h}$ on the surface of the agar plate, prepared by dissolving $2 \%(\mathrm{w} / \mathrm{v})$ agar in warmed isotonic phosphate buffer of $\mathrm{pH} 6.5$ under stirring and then pouring the solution into the Petri dish and allowed to stand till gelling at room temperature. The surface $\mathrm{pH}$ was measured by means of $\mathrm{pH}$ paper placed on the surface of the fabricated contact lenses. The average surface $\mathrm{pH}$ was reported in Table 4.

\section{Folding endurance}

Folding endurance is the study to check the folding capacity of the ocular films when subjected to frequent extreme conditions such blinking of eye. The fabricated ocular films were folded and unfolded completely from the center several times until the film was broken. The number of folding and unfolding require to break the film completely was noted as folding endurance [37]. The average folding endurance was reported in Table 4.

\section{Breaking on elongation}

Break on elongation at break of the fabricated lenses were determined according to ASTM D882-12 using a universal testing machine with a load cell of $2 \mathrm{~kg}$, a crosshead speed of $20 \mathrm{~mm} / \mathrm{min}$, and a gauge length of $10 \mathrm{~mm}[38,39]$ Table 4 .

Table 3: Effect of drug solution pH on drug loading capacity

\begin{tabular}{lllll}
\hline Formulation & \multicolumn{4}{l}{ Drug loading $(\boldsymbol{\mu g})$ of ocular film } \\
\cline { 2 - 5 } & $\mathbf{p H ~ 6 . 5}$ & $\mathbf{p H ~ 7 . 0}$ & $\mathbf{p H ~ 7 . 5}$ & $\mathbf{p H ~ 8 . 0}$ \\
\hline OF -01 & $09.75 \pm 0.32$ & $09.12 \pm 0.28$ & $08.84 \pm 0.42$ & $08.84 \pm 0.42$ \\
OF -02 & $10.38 \pm 0.26$ & $09.74 \pm 0.30$ & $09.13 \pm 0.40$ & $09.13 \pm 0.40$ \\
OF -03 & $12.86 \pm 0.52$ & $12.01 \pm 0.24$ & $11.46 \pm 0.19$ & $11.46 \pm 0.19$ \\
OF -04 & $28.56 \pm 0.23$ & $28.12 \pm 0.28$ & $27.63 \pm 0.32$ & $27.63 \pm 0.32$ \\
OF -05 & $18.89 \pm 0.28$ & $18.42 \pm 0.36$ & $17.62 \pm 0.47$ & $17.62 \pm 0.47$ \\
OF -06 & $17.32 \pm 0.22$ & $17.02 \pm 0.42$ & $16.67 \pm 0.28$ & $16.67 \pm 0.28$ \\
OF -07 & $18.56 \pm 0.18$ & $18.28 \pm 0.23$ & $17.86 \pm 0.30$ & $17.86 \pm 0.30$ \\
OF -08 & $18.92 \pm 0.23$ & $18.48 \pm 0.32$ & $17.94 \pm 0.27$ & $17.94 \pm 0.27$ \\
OF -09 & $19.23 \pm 0.44$ & $19.01 \pm 0.28$ & $18.43 \pm 0.36$ & $18.43 \pm 0.36$ \\
\hline
\end{tabular}

Condition: Moxifloxacin solution (0.5), Time 3 h; SD: Standard deviation; $n=3$

\section{Bio-adhesive strength}

Construction of the test assembly

A student dispensing balance was used to construct the basic structure of the assembly to evaluate the bio-adhesive strength of the fabricated ocular film [40]. The dispensing balance's right-side pan was replaced with a stainless-steel block attached with string, required a same weight as the left-side pan (Fig. 2).

\section{Determination of adhesion force}

The goat conjunctival membrane was washed and was tightly tied over a stainless-steel block; this assembly was attached to the right-side pan using a string, and another conjunctival membrane was tied to another stainless-steel block with the conjunctival mucosa side facing upward. The stainless-steel block with the conjunctival membrane was placed inside a glass beaker with a sufficient quantity of simulated tear fluid (STF) at $7.2 \mathrm{pH}$, such that the STF reaches the surface of the conjunctival membrane and keeps it moist. This beaker was placed under the rightside pan of the balance. An ocular film was stuck onto the conjunctival membrane with a drop of water, and the assembly with the conjunctival membrane attached to the right-side pan was pressed over the insert placed over the conjunctival membrane stainless steel block placed inside the beaker. The assembly was kept in this position for $3 \mathrm{~min}$, and then, weights were added gradually to the left pan till the ocular film separated from the mucosal surface completely. The excess weight of the pan that is the total, gives the measure of the force of detachment of the film in grams. From this, the bio-adhesion strength can be calculated by the formula force of adhesion $(\mathrm{N})=\mathrm{F} \times 9.81$. Where $\mathrm{F}$ is the excess weight added to the pan, a fresh portion of tissue was used for each measurement [40]. The average bio-adhesive strength of all the batches was reported in Table 4 .

\section{Drug content}

The amount of drug loaded into the films was calculated from the difference between the amount of initial drug in the solution and the amount of drug remaining in the solution after film soaking. The amount of free drug remaining in the solution was determined using a UV-visible spectrophotometer at $293 \mathrm{~nm}$, and the results were noted in Table 4.

\section{Surface morphology}

The surface morphology and cross section of the moxifloxacin loaded lenses were examined by a scanning electron microscope (SEM) to confirm drug loading. The samples were sputter-coated with platinum using a plasma sputter coater to obtain fine images and minimize electron charging on the surface (Figs. 3 and 4 ).

\section{In vitro drug release studies}

In vitro drug release studies were carried out at $37^{\circ} \mathrm{C} \pm 1^{\circ} \mathrm{C}$. The moxifloxacin loaded ocular films were placed into a pipette tip,

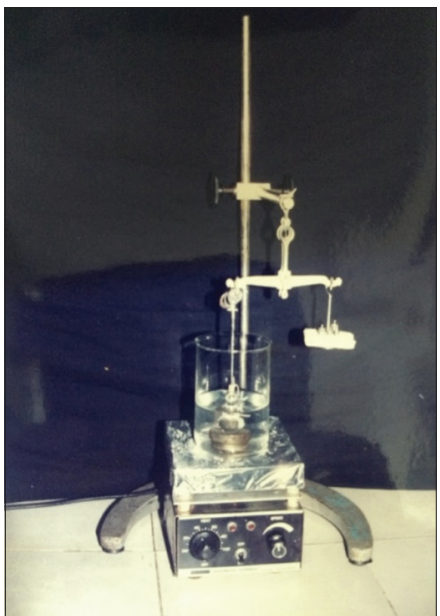

Fig. 2: Assembly to determine bio-adhesive strength 


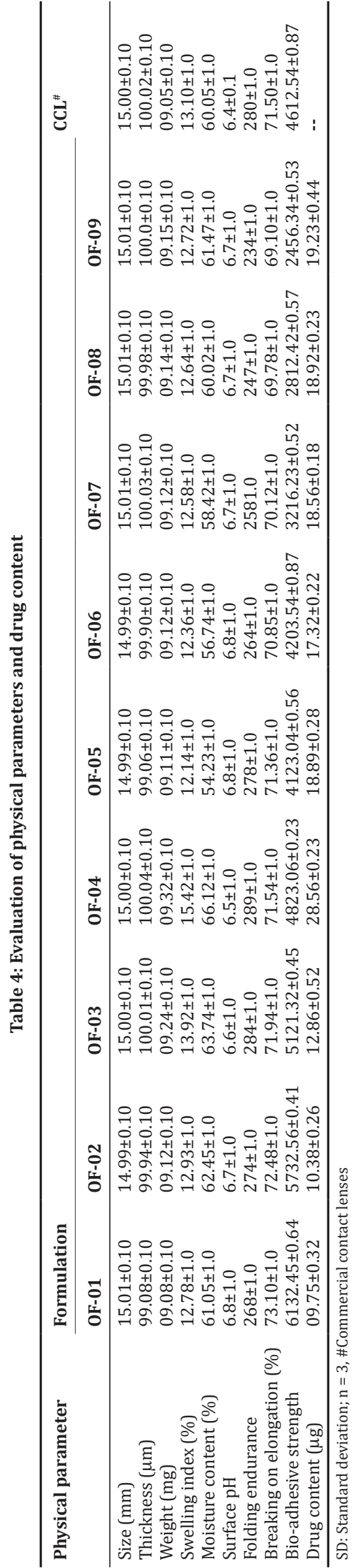

with a fluid cavity of $50 \mu \mathrm{l}$. The pipette tip was then inserted into a disposable sample collection tube and fed using STF (pH 7.4) at a flow rate of $10 \mathrm{ml} / \mathrm{min}$ using a micro drop infusion set. Sodium chloride $0.67 \mathrm{~g}$, sodium bicarbonate $0.2 \mathrm{~g}$, calcium chloride $0.008 \mathrm{~g}$, in $100 \mathrm{ml}$ of deionized water were the contents of STF. At predetermined time intervals (1-12 h), the disposable sample collection tube was taken and replaced with a new sample collection tube. The amount of drug released in sample collection tube was then determined using a UVvisible spectrophotometer at $293 \mathrm{~nm}$ (Table 5). The release profile of a drug was evaluated by plotting graphs of cumulative drug release versus time (Fig. 5).

\section{RESULTS AND DISCUSSION}

The ocular films were fabricated following the optimum conditions. The fabricated ocular films fulfil the requirements of the materials standard for disposable contact lenses as ocular drug delivery.

\section{Fabrication of ocular films}

The ocular films were fabricated using different ratio of chitosan shrimp solution and activated silk fibroin along with PEG 400 (Table 1).

\section{Drug loading capacity}

Due to its cost effectiveness and simplicity, the soaking method is the most conventional and effective way of loading a drug into the ocular films. To attain this, the fabricated ocular films were dipped in $2 \mathrm{ml}$ of $0.5 \%$ Moxifloxacin solution and the drug was allowed to get adsorbed into the ocular films' surface and core. It was found that the drug loading capacity of the ocular films depends on three important factors, such as the composition of the film, dipping time, and drug solution $\mathrm{pH}$. To study the effect of drug loading time, the films were soaked in $0.5 \%$ moxifloxacin solution, $\mathrm{pH}$ 6.5, with varying soaking time from 1 to $24 \mathrm{~h}$ (Table 2). It was found that the drug loading to ocular films increased by increasing the soaking time from 1 to $12 \mathrm{~h}$ and reached equilibrium at $3 \mathrm{~h}$ for all fabricated films, compared to conventional contact lenses which require a high drug loading time of 12-24 h (Fig. 6).

The drug loading capacity of the ocular films was studied at a varying $\mathrm{pH}$ range of drug solution from 6.5 to 8.0 for $3 \mathrm{~h}$. The fabricated ocular films were soaked in $2 \mathrm{ml}$ of $0.5 \%$ moxifloxacin solution with a $\mathrm{pH}$ range of 6.5 to 8.0 for $3 \mathrm{~h}$. It was noted that the increasing drug solution $\mathrm{pH}$ would decrease the drug loading capacity of the ocular films (Table 3). All the fabricated ocular films represent the maximum drug loading at pH 6.5 and the minimum drug loading at $\mathrm{pH}$ 8.0.

The observations suggest that the moxifloxacin was loaded onto all fabricated ocular films. This indicates the inter-molecular interaction, likely due to hydrogen bonding and ionic interaction, among the drug and the film forming agents. However, it was found that the drug loading was increased with increasing the ratio of activated silk fibroin in the film. The formulation no. OF-01 shows the lowermost drug loading capacity. On the other hand, the formulation no. OF-04 exhibited the highest drug loading capacity, which may be due to the high content of activated silk fibroin resulting in a high porous portion. Accordingly, the high porous portion offers more space in the film, which leads to enhanced drug adsorption in the film's surface and core.

\section{Physical evaluation of the ocular films}

The fabricated ocular films were evaluated for physical properties and compared with typical commercial contact lenses. The physical properties of the drug loaded ocular showed no significant difference when compared with commercial contact lenses (Table 4). The fabricated ocular films were found to be in a range of $14.98 \pm 0.10$ to $15.01 \pm 0.10 \mathrm{~mm}$ round with uniformity in size and compliant with commercial contact lenses of similar size. They have a comparable thickness range between $99.06 \pm 0.34$ and $100.04 \pm 0.43 \mu \mathrm{m}$, with commercial contact lenses of $50-200 \mu \mathrm{m}$.

The fabricated ocular films were weighed within a range limit of $9.08 \pm 0.10$ and $9.32 \pm 0.10 \mathrm{mg}$. They showed high visible light 

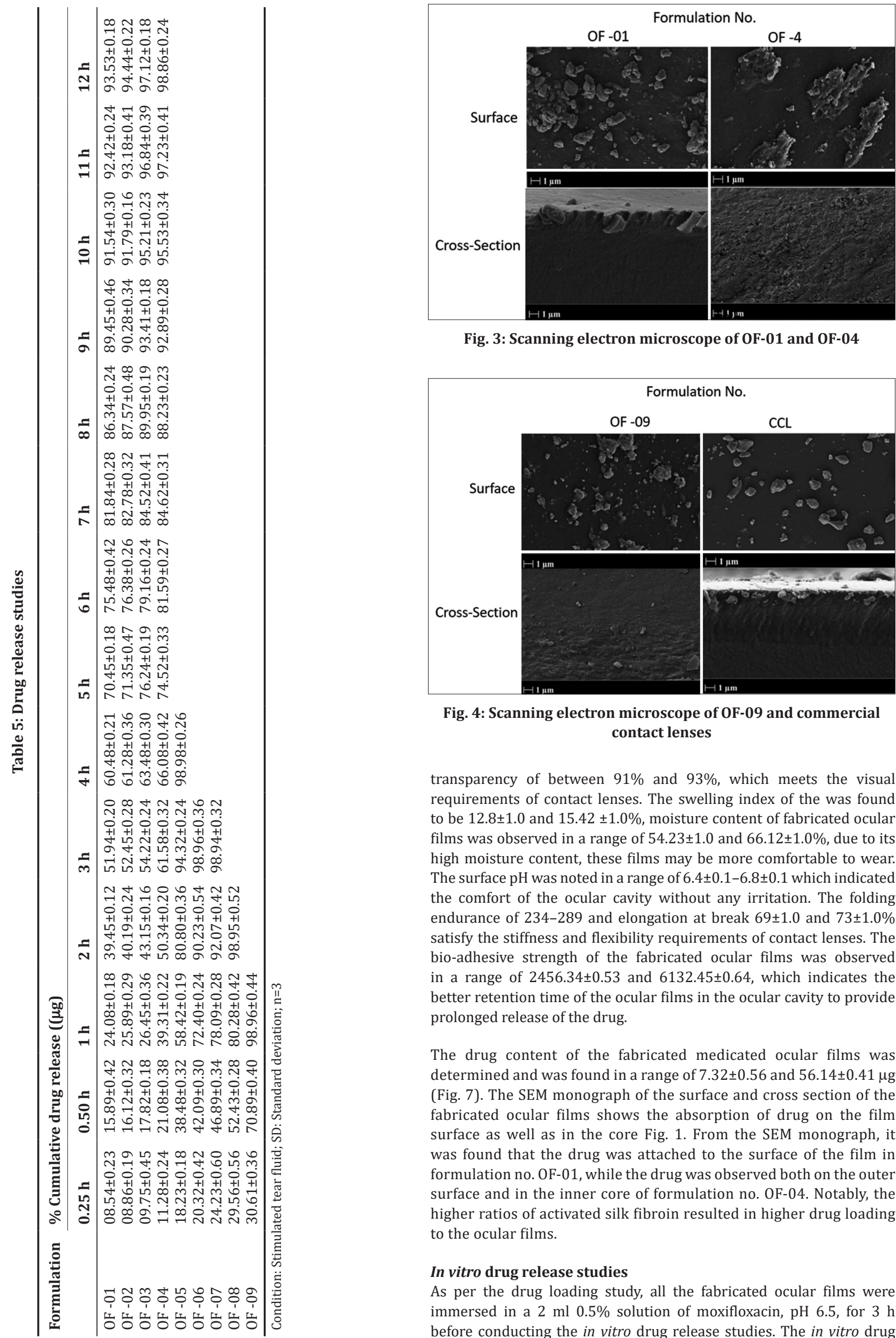

Fig. 3: Scanning electron microscope of OF-01 and OF-04

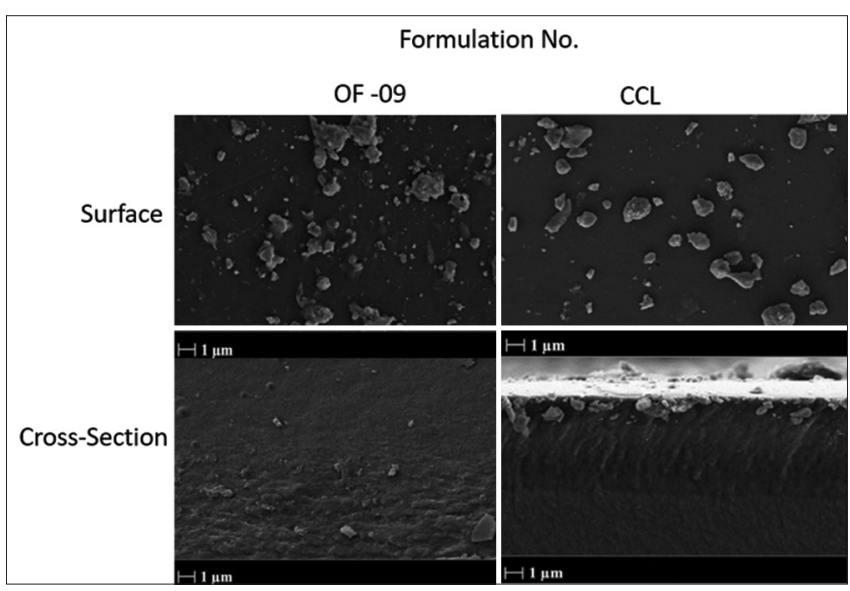

Fig. 4: Scanning electron microscope of OF-09 and commercial contact lenses

transparency of between $91 \%$ and $93 \%$, which meets the visual requirements of contact lenses. The swelling index of the was found to be $12.8 \pm 1.0$ and $15.42 \pm 1.0 \%$, moisture content of fabricated ocular films was observed in a range of $54.23 \pm 1.0$ and $66.12 \pm 1.0 \%$, due to its high moisture content, these films may be more comfortable to wear. The surface $\mathrm{pH}$ was noted in a range of $6.4 \pm 0.1-6.8 \pm 0.1$ which indicated the comfort of the ocular cavity without any irritation. The folding endurance of 234-289 and elongation at break $69 \pm 1.0$ and $73 \pm 1.0 \%$ satisfy the stiffness and flexibility requirements of contact lenses. The bio-adhesive strength of the fabricated ocular films was observed in a range of $2456.34 \pm 0.53$ and $6132.45 \pm 0.64$, which indicates the better retention time of the ocular films in the ocular cavity to provide prolonged release of the drug.

The drug content of the fabricated medicated ocular films was determined and was found in a range of $7.32 \pm 0.56$ and $56.14 \pm 0.41 \mu \mathrm{g}$ (Fig. 7). The SEM monograph of the surface and cross section of the fabricated ocular films shows the absorption of drug on the film surface as well as in the core Fig. 1. From the SEM monograph, it was found that the drug was attached to the surface of the film in formulation no. OF-01, while the drug was observed both on the outer surface and in the inner core of formulation no. OF-04. Notably, the higher ratios of activated silk fibroin resulted in higher drug loading to the ocular films.

\section{In vitro drug release studies}

As per the drug loading study, all the fabricated ocular films were immersed in a $2 \mathrm{ml} 0.5 \%$ solution of moxifloxacin, $\mathrm{pH} 6.5$, for $3 \mathrm{~h}$ before conducting the in vitro drug release studies. The in vitro drug 


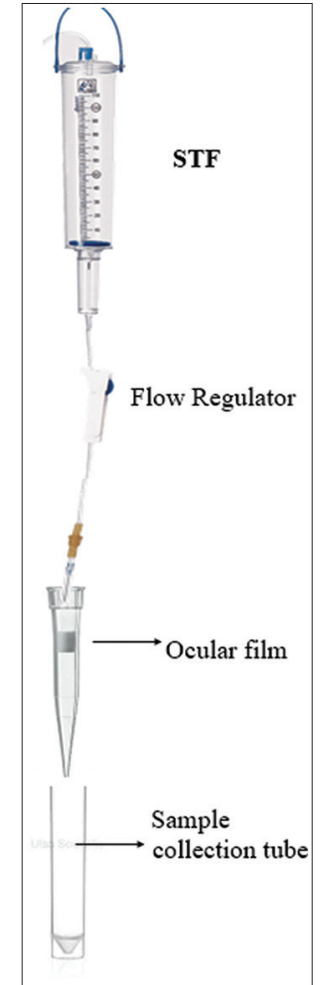

Fig. 5: Assembly for in-vitro release study

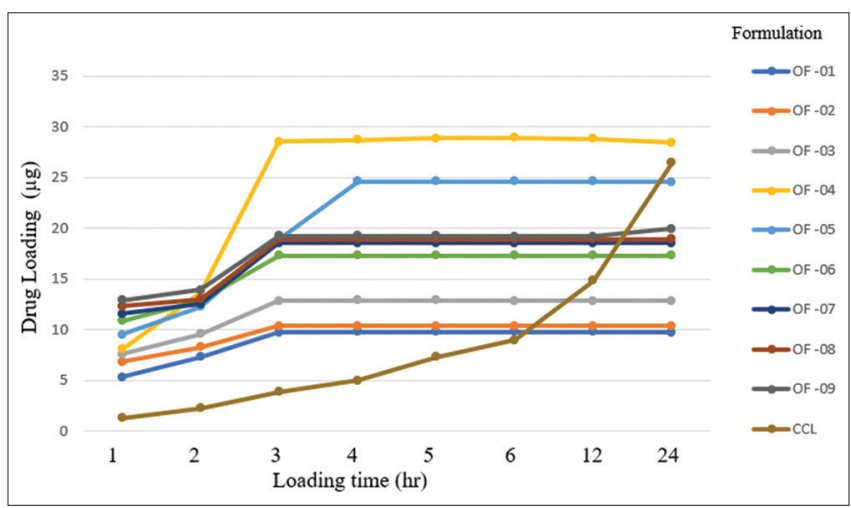

Fig. 6: Drug loading capacity of ocular films versus time

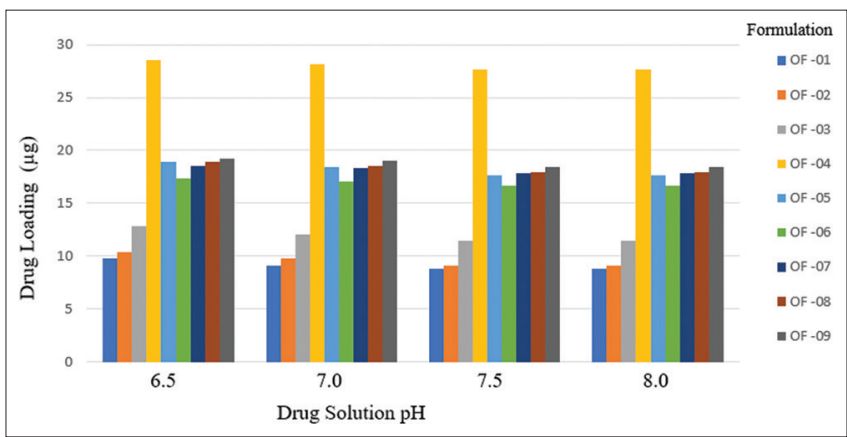

Fig. 7: Drug loading capacity of ocular films versus pH

release studies were conducted for $12 \mathrm{~h}$ and are reported in Table 5 . The graph of cumulative percentage released and time were plotted in the figure, which demonstrates that the formulations no. OF-01 to OF-03 showed a slow release that is $08.54 \pm 0.23 \mu \mathrm{g}$ to $97.12 \pm 0.18 \mu \mathrm{g}$ in $12 \mathrm{~h}$ release studies which indicates that high chitosan content slows

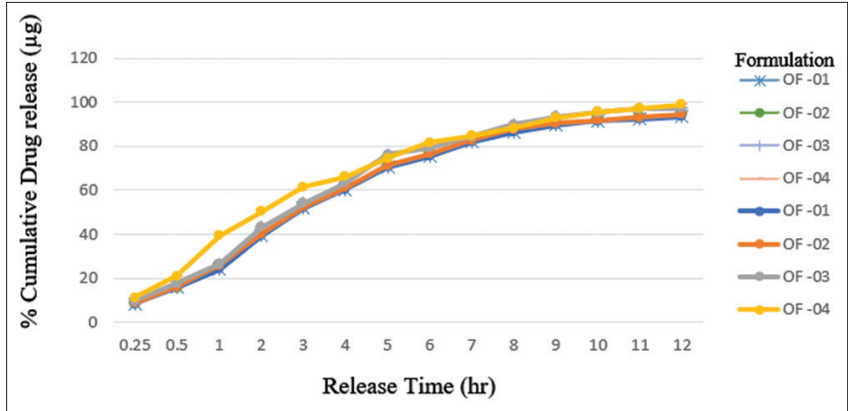

Fig. 8: In-vitro drug release study of ocular films (OF-01 - OF-04)

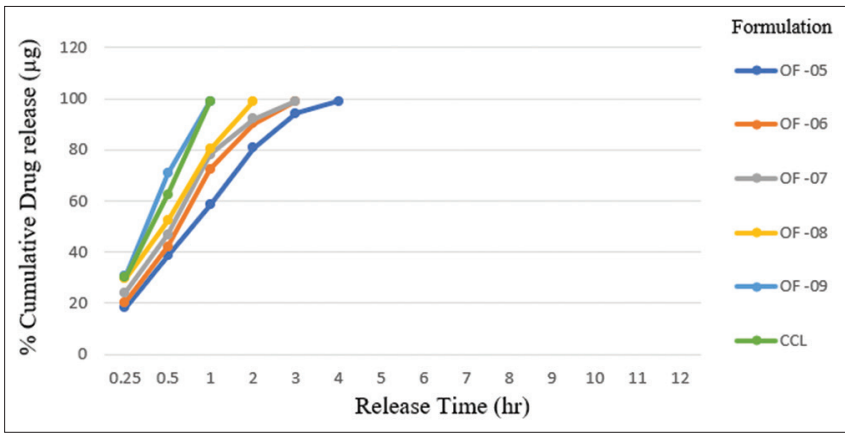

Fig. 9: In-vitro drug release study of ocular films (OF-05 - 0F-09 and commercial contact lenses)

the drug release due to locking of the drug in the chitosan matrix and unavailability of porosity in the films (Figs. 8 and 9).

Whereas the formulation no. OF-04 containing 60:40 of chitosan and silk fibroin shows an ideal drug release pattern and the drug release range is $11.28 \pm 0.24 \mu \mathrm{g}$ to $98.86 \pm 0.24 \mu \mathrm{g}$ in $12 \mathrm{~h}$, which explains the phenomenon that the drug absorption locations affect the drug release profile significantly. Noticeably, the drug located on the film surface is immediately released into the media, contributing to the fast release phase. Drugs that stayed in the inner core, on the other hand, took a bit longer to dissolve and diffuse to the outer surface, resulting in a longer release phase. Further, the formulations no. OF-05 to OF -09 showed fast release due to the very high porosity of the film, which resulted due to the high content of silk fibroin. Thus, the formulation OF-04 was selected as the optimized formulation.

\section{CONCLUSION}

Moxifloxacin hydrochloride was successfully loaded into the fabricated ocular film by the soaking method with a short loading time of $3 \mathrm{~h}$. The drug loading did not affect the essential contact lens properties of the fabricated ocular films. Basically, the composition of ocular films altered the drug loading capacity and the drug released profile. Increasing the silk fibroin content enhances the drug loading capacity of the film but shortens the release duration. Consequently, an ideal released characteristic within a therapeutic level of up to $12 \mathrm{~h}$ was observed with the 60:40 (Chitosan: Silk fibroin). The fabricated ocular films are promising novel biomaterials for producing medicated disposable contact lenses-based ophthalmic delivery systems for daily use, which will be beneficial in reducing drug dose related side effects, administration frequency, and improving patient compliance as compared to conventional eye drops and eye ointments.

\section{ACKNOWLEDGMENT}

The author thanks the Department of Pharmaceutics, Mar Dioscorus College of Pharmacy, Sreekariyam, Thiruvananthapuram, Kerala, and Maa Pharmaceuticals and Research Center, Ajmer, Rajasthan, for 
providing the required facilities and support to carry out this research work.

\section{AUTHORS' CONTRIBUTION}

All the authors have made equal contribution.

\section{CONFLICTS OF INTEREST}

The authors declare no conflict of interest.

\section{AUTHOR'S FUNDING}

NA.

\section{REFERENCES}

1. Lang JC, Ocular drug delivery conventional ocular formuations. Adv Drug Deliv Rev 1995;16:39-43.

2. Bourlais CL, Acar L, Zia H, Sado PA, Needham T, Leverge R. Ophthalmic drug delivery systems. Prog Ret Eye Res 1998;17:33-58.

3. Ali M, Byrne ME. Challenges and solutions in topical ocular drug delivery systems. Expert Opin Drug Deliv 2008;1:145-61.

4. Deshpande SG, Shirolkar SJ. Sustained release ophthalmic formulations of pilocarpine. J Pharm Pharmacol 1989;41:197-200.

5. Geroski DH, Edelhauser HF, Drug delivery for posterior segment eye disease. Invest Ophthalmol Vis Sciences, 2000; 41:961-4.

6. Hyun JJ, Anuj C. Ophthalmic drug delivery by contact lenses. Expert Rev Ophthalmol 2012;7:199-201.

7. Winfield AJ, Jessiman D, Williams A, Esakowitz L. A study of the causes of non-compliance by patients prescribed eyedrops. $\mathrm{Br} \mathrm{J}$ Ophthalmol 1990;74:477-80.

8. Lin HR, Sung KC. Carbopol/pluronicphasechange solutions for ophthalmic drug delivery. J Control Release 2000;69:379-88.

9. Barbu E, Verestiuc L, Nevell TG, Tsibouklis J, Tsibouklis J. Polymericmaterials for ophthalmic drug delivery: Trends and perspectives. J Mater Chem 2006;16:3439-43.

10. Gulsen D, Chauhan A. Dispersion of microemulsion drops in HEMA hydrogel: A potential ophthalmic drug delivery vehicle. Int J Pharm 2005;292:95-117.

11. Xinming L, Yingde C, Lloyd AW, Mikhalovsky SV, Sandeman SR, Howel CA, et al. Polymeric hydrogels for novel contact lens-based ophthalmic drug delivery systems: A review. Cont Lens Anterior Eye 2008;31:57-64.

12. Tieppo A, Pate KM, Byrne ME. In vitro controlled release of an antiinflammatory from daily disposable therapeutic contact lenses under physiological ocular tear flow. Eur J Pharm Biopharm 2012;81:170-7.

13. Guzman-Aranguez A, Colligris B, Pintor JJ. Contact lenses: Promising devices for ocular drug delivery. J Ocul Pharmacol Ther 2013;29:189-99.

14. Maulvi FA, Soni TG, Shah DO. A review on therapeutic contact lenses for ocular drug delivery. Drug Dev 2016;23:3017-26.

15. McDermott ML, Chandler JW. Therapeutic uses of contact lenses. Surv Ophthalmol 1989;33:381-94

16. Karlgard CC, Wong NS, Jones LW, Moresoli C. In vitro uptake and release studies of ocular pharmaceutical agents by siliconcontaining and p-HEMA hydrogel contact lens materials. Int J Pharm 2003;257:141-51.

17. Lee D, Cho S, Park CH, Kwon I. Ocular drug delivery through pHEMA-hydrogel contact lenses co-loaded with lipophilic vitamins. Sci Rep 2016;6:34194

18. Peng CC, Kim J, Chauhan A. Extended delivery of hydrophilic drugs from silicone-hydrogel contacts lenses containing Vitamin E diffusion barriers. Biomaterials 2010;31:4032-47.

19. Sharma J, Majumar DK. Moxifloxacin loaded contact lens for ocular delivery an in vitro study. Int J Pharm Pharm Sci 2011;4:605-9.

20. Hsu KH, Fentzke RC, Chauhan A. Feasibility of corneal drug delivery of cysteamine using Vitamin E modified silicone hydrogel contact lenses. Eur J Pharm Biopharm 2013;85:531-40.

21. Moxifloxacin Hydrochloride. The American Society of Health-System Pharmacists; 2017

22. British Medical Association. British National Formulary: BNF 69. 69 ${ }^{\text {th }}$ ed., Vol. 408. British Medical Association; 2015. p. 757.

23. Akiyoshi A. Dissolution of silk fibroin with calcium chloride/ethanol aqueous solution. J Sericol Sci Japan 1998;67:91-4.

24. Yamada H, Nakao H, Takasu Y, Tsubouchi K. Preparation of undegraded native molecular fibroin solution from silkworm cocoons. Mater Sci Eng 2001;14:41-6.

25. Jeencham R, Sutheerawattananonda M, Tiyaboonchai W. Preparation and characterization of chitosan/regenerated silk fibroin (CS/RSF) films as a biomaterial for contact lenses-based ophthalmic drug delivery system. Int J Appl Pharm 2019;11:275-84.

26. Kim KM, Son JH, Kim SK, Weller CL, Hanna MA. Properties of chitosan films as a function of $\mathrm{pH}$ and solvent type. J Food Sci 2006;71:119-24.

27. Jung HJ, Abou-Jaoude M, Carbia BE, Plummer C, Chauhan A. Glaucoma therapy by extended release of timolol from nanoparticle loaded siliconehydrogel contact lenses. J Control Release 2013;165:82-9.

28. Bodaghi B. Diclofenac sodium $0.1 \%$ ophthalmic solution: Update on pharmacodynamics, clinical interest and safety profile. Expert Rev Ophthalmol 2008;3:139-48.

29. Kearns VR, Williams RL. Drug delivery systems for the eye. Expert Rev Med Devices 2009;6:277-90.

30. Li CC, Chauhan A. Modeling ophthalmic drug delivery by soaked contact lenses. Ind Eng Chem Res 2006;45:3718-34.

31. Peterson RC, Wolffsohn JS, Nick J, Winterton L, Lally J. Clinical performance of daily disposable soft contact lenses using sustained release technology. Contact Lens Anterio Eye 2006;29:127-34.

32. Bengani LC, Hsu KH, Gause S, Chauhan A. Contact lenses as a platform for ocular drug delivery. Expert Opin Drug Deliv 2013;10:1483-96.

33. Maulvi FA, Soni TG, Shah DO. Effect of timolol maleate concentration on uptake and release from hydrogel contact lenses using soaking method. J Appl Pharm Sci 2015;2:1-22

34. Gonzalez-Meijome JM, Compa n-Moreno V, Riande E. Determination of oxygen permeability in soft contact lenses using a polarographic method: Estimation of relevant physiological parameters. Ind Eng Chem Res 2008;47:3619-29.

35. Lai CF, Li JS, Fang YT, Chien CJ, Lee CH. UV and blue-light anti-reflective structurally colored contact lenses based on a copolymer hydrogel with amorphous array nanostructures. RSC Adv 2018;8:4006-13

36. Tranoudis I, Efron N. Tensile properties of soft contact lens materials. Cont Lens Anterior Eye 2004;27:177-91

37. Patel UL, Chotai NP, Nagda CD. Design and evaluation of polymeric ocular drug delivery system for controlled delivery of moxifloxacin hydrochloride: In vitro and in vivo evaluation. Active Pharm Sci 2010;52:523-35.

38. Horst CR, Brodland B, Jones LW, Brodland GW. Measuring the modulus of silicone hydrogel contact lenses. Optom Vis Sci 2012;89:1468-76.

39. Selby A, Maldonado-Codina C, Derby B. Influence of specimen thickness on the nanoindentation of hydrogels: Measuring the mechanical properties of soft contact lenses. J Mech Behav Biomed Mater 2014;35:144-56.

40. Gevariya H, Patel J, Girhepunje K, Pal R. Sustained ophthalmic delivery of levofloxacin from once a day ocuserts. Int J Pharm Pharm Sci $2009 ; 1: 2432$ 